\title{
DIETARY NITRATE SUPPLEMENTATION IMPROVES SPRINT AND HIGH-INTENSITY INTERMITTENT RUNNING PERFORMANCE
}

Christopher Thompson ${ }^{1}$, Anni Vanhatalo ${ }^{1}$, Harry Jell ${ }^{1}$, Jonathan Fulford ${ }^{2}$, James Carter ${ }^{3}$, Lara Nyman ${ }^{3}$, Stephen J. Bailey ${ }^{1}$, Andrew M. Jones ${ }^{1}$

Affiliations: ${ }^{1}$ Sport and Health Sciences and ${ }^{2}$ NIHR Exeter Clinical Research Facility, University of Exeter, Heavitree Road, Exeter, UK; ${ }^{3}$ Gatorade Sports Science Institute, PepsiCo R\&D, Barrington IL, USA.

Running head: Dietary nitrate and sprint running performance

\section{Address for correspondence:}

Andrew M. Jones, Ph.D.

University of Exeter, St. Luke’s Campus

Exeter, Devon, EX1 2LU, UK.

E-mail: a.m.jones@exeter.ac.uk

Tel: 01392 722886; Fax: 01392264726 


\section{ABSTRACT}

The influence of dietary nitrate $\left(\mathrm{NO}_{3}{ }^{-}\right)$supplementation on indices of maximal sprint and intermittent exercise performance is unclear. Purpose: To investigate the effects of $\mathrm{NO}_{3}{ }^{-}$ supplementation on sprint running performance, and cognitive function and exercise performance during the sport-specific Yo-Yo Intermittent Recovery level 1 test (IR1). Methods: In a double-blind, randomised, crossover study, 36 male team-sport players received $\mathrm{NO}_{3}^{-}$-rich $\left(\mathrm{BR} ; 70 \mathrm{~mL} \cdot \mathrm{day}^{-1} ; 6.4 \mathrm{mmol}\right.$ of $\mathrm{NO}_{3}^{-}$), and $\mathrm{NO}_{3}{ }^{-}$-depleted (PL; 70 $\mathrm{mL} \cdot$ day $^{-1} ; 0.04 \mathrm{mmol} \mathrm{NO}_{3}^{-}$) beetroot juice for 5 days. On day 5 of supplementation, subjects completed a series of maximal 20-m sprints followed by the Yo-Yo IR1. Cognitive tasks were completed prior to, during and immediately following the Yo-Yo IR1. Results: BR improved sprint split times relative to PL at 20 m (1.2\%; BR 3.98 \pm 0.18 vs. PL $4.03 \pm 0.19$ s; $P<0.05), 10 \mathrm{~m}(1.6 \%$; BR $2.53 \pm 0.12$ vs. $\mathrm{PL} 2.57 \pm 0.19$ s; $P<0.05)$ and $5 \mathrm{~m}(2.3 \%$; BR $1.73 \pm 0.09$ vs. PL $1.77 \pm 0.09$ s; $P<0.05)$. The distance covered in the Yo-Yo IR1 test improved by $3.9 \%$ (BR $1422 \pm 502$ vs. PL $1369 \pm 505 \mathrm{~m} ; P<0.05$ ). The reaction time to the cognitive tasks was shorter in BR $(615 \pm 98 \mathrm{~ms})$ than PL $(645 \pm 120 \mathrm{~ms} ; P<0.05)$ at rest but not during the Yo-Yo IR1. There was no difference in response accuracy. Conclusions: Dietary $\mathrm{NO}_{3}{ }^{-}$ supplementation enhances maximal sprint and high-intensity intermittent running performance in competitive team sport players. Our findings suggest that $\mathrm{NO}_{3}{ }^{-}$ supplementation has the potential to improve performance in single-sprint or multiple-sprint (team) sports.

Key Words: nitric oxide, beetroot juice, running speed, cognitive performance 


\section{INTRODUCTION}

Nitric oxide (NO) is a gaseous signalling molecule that regulates several physiological processes that are important to exercise performance, including vasodilation, mitochondrial respiration and skeletal muscle contractility (Stamler and Meissner, 2001; Umbrello et al. 2013). NO can be generated through the nitric oxide synthase (NOS)-catalysed oxidation of L-arginine and through the $\mathrm{O}_{2}$-independent, one-electron reduction of nitrite $\left(\mathrm{NO}_{2}{ }^{-}\right)$. The reduction of $\mathrm{NO}_{2}^{-}$to $\mathrm{NO}$ is enhanced in hypoxia and acidosis (Lundberg et al. 2008; van Faassen et al. 2009) and, since contracting skeletal muscles become increasingly hypoxic and acidic during exercise, NOS activity may be reduced and $\mathrm{NO}_{2}{ }^{-}$reduction may become an increasingly important source of NO during exercise (Lundberg and Weitzberg 2010). Increasing plasma $\left[\mathrm{NO}_{2}{ }^{-}\right]$via $\mathrm{NO}_{3}{ }^{-}$supplementation has been reported to improve muscle oxygenation (Bailey et al. 2009; Masschelein et al. 2012), muscle metabolic efficiency (Bailey et al. 2010; Larsen et al. 2011; Fulford et al. 2013) and contractile function (Hernandez et al, 2012; Haider and Folland et al. 2014; Coggan et al. 2015), and to improve endurance exercise capacity at least in participants that are not highly trained (Bailey et al. 2009; Lansley et al. 2011; Cermak et al. 2012).

Recent evidence suggests that $\mathrm{NO}_{3}{ }^{-}$supplementation has the potential to preferentially enhance physiological responses in type II (fast-twitch), compared to type I (slow-twitch), skeletal muscle (Jones, 2014a). Indeed, increased calcium handling proteins and contractile force has been observed in type II, but not type $\mathrm{I}$, mouse skeletal muscle after $\mathrm{NO}_{3}{ }^{-}$ supplementation (Hernandez et al. 2012). In addition, $\mathrm{NO}_{3}{ }^{-}$supplementation increased hind limb blood flow during exercise in rats, with this additional bulk blood flow being selectively directed towards type II muscle fibres (Ferguson et al. 2013). Human studies suggest that $\mathrm{NO}_{3}{ }^{-}$supplementation can increase evoked explosive force production (Haider and Folland. 2014) and maximal voluntary power production (Coggan et al. 2015) in the knee extensors, 
and can increase maximal sprint cycling power output (Rimer et al. 2015) and $180 \mathrm{~m}$ sprint running performance (Sandbakk et al., 2015). However, while these findings suggest that $\mathrm{NO}_{3}{ }^{-}$supplementation has the potential to improve sprinting performance, the effects of $\mathrm{NO}_{3}{ }^{-}$ supplementation on sprint running performance over short distances that reflect those exhibited during team sports match-play (10-20 m; Spencer et al. 2004; 2005) have yet to be investigated.

The activity pattern during team sports, such as football, rugby and hockey, is characterised by short-duration bouts of high-intensity exercise interspersed with brief recovery periods (Spencer et al. 2004). Since this pattern of high-intensity intermittent exercise is associated with significant type II muscle recruitment (Krustrup et al. 2006) and, since $\mathrm{NO}_{3}{ }^{-}$ supplementation can enhance physiological processes in type II muscle (Hernandez et al. 2012; Ferguson et al. 2013), $\mathrm{NO}_{3}{ }^{-}$supplementation has the potential to enhance team-sportspecific high-intensity intermittent exercise performance. Consuming a very large $\mathrm{NO}_{3}{ }^{-}$dose (29 mmol) over 36 hours prior to exercise was shown to improve performance during the YoYo intermittent recovery level 1 test (Yo-Yo IR1; Wylie et al. 2013a), a well-established and ecologically valid test widely used to mimic the high-intensity running bouts of football match-play (Bangsbo et al. 2008). Performance can also be improved in short-duration intermittent cycling sprints after supplementation with a large $\mathrm{NO}_{3}{ }^{-}$dose $\left(\sim 8-13 \mathrm{mmol} \mathrm{NO}_{3}{ }^{-}\right.$ per day, over 3-7 days; Thompson et al. 2015; Wylie et al. 2016), but not with acute consumption of a small $\mathrm{NO}_{3}{ }^{-}$dose $\left(\sim 5 \mathrm{mmol} \mathrm{NO}_{3}{ }^{-}\right.$per day; Martin et al., 2014). However, the effects of short-term supplementation with a moderate $\mathrm{NO}_{3}{ }^{-}$dose on performance during a team-sport-specific intermittent performance test (i.e., a supplementation procedure that has been shown to be effective at improving continuous endurance exercise performance (Bailey et al. 2009; 2010; Lansley et al. 2011; Vanhatalo et al. 2010)), remains to be determined. 
The ability to make quick and accurate decisions whilst simultaneously performing highintensity running exercise is a key determinant of team sport performance. It has been reported that acute low dose ( $\sim 5 \mathrm{mmol}) \mathrm{NO}_{3}{ }^{-}$ingestion can increase resting brain blood flow and improve resting cognitive performance (Wightman et al. 2015), and that $\mathrm{NO}_{3}{ }^{-}$ supplementation (12.8 $\mathrm{mmol} \mathrm{NO}_{3}{ }^{-}$per day for 7 days) can improve reaction time to cognitive tasks during prolonged intermittent sprint-cycling (Thompson et al. 2015). However, the effect of $\mathrm{NO}_{3}^{-}$supplementation on cognitive performance during an exercise test that simulates the movement patterns of team sport match-play has not been investigated.

The purpose of this study was to assess the effects of $\mathrm{NO}_{3}{ }^{-}$supplementation on team-sportspecific exercise performance variables and cognitive function before, during and after a YoYo IR1 test. We hypothesised that, compared to a placebo supplement, $\mathrm{NO}_{3}{ }^{-}$supplementation would: 1) improve sprint running performance; and 2) improve exercise and cognitive performance during a Yo-Yo IR1 test.

\section{METHODS}

\section{Subjects}

Thirty-six male team-sport players from local football, rugby and hockey teams (mean \pm SD: age $24 \pm 4$ years, height $1.80 \pm 0.07 \mathrm{~m}$, body mass $80 \pm 10 \mathrm{~kg}$ ) volunteered to participate. The subjects trained (5-10 hours per week) and participated regularly in university and local league competitions. None of the subjects were supplementing their diet with any putative ergogenic aid for 6 months prior to the start of the study. Following an explanation of the experimental procedures, associated risks, potential benefits and likely value of possible findings, subjects gave their written informed consent to participate. The study was approved by the Institutional Research Ethics Committee and conformed to the code of ethics of the Declaration of Helsinki. 


\section{Experimental design}

Subjects initially visited the laboratory to be screened and familiarized to the testing procedures. This included the Yo-Yo intermittent recovery level 1 test (Yo-Yo IR1) until task failure, $20 \mathrm{~m}$ sprint efforts and the computer-based cognitive tasks. The total distance covered in the Yo-Yo IR1 test was used to calculate the subject's 75\% distance which served as a time-point for cognitive assessment in the experimental visits. In a double-blind, randomized, crossover design, subjects were then assigned to receive $\mathrm{NO}_{3}{ }^{-}$-rich beetroot juice (BR) and a $\mathrm{NO}_{3}{ }^{-}$-depleted beetroot juice (PL) for 5 days with a wash-out period of 7 days separating the two supplementation periods. On day 5 of each supplementation period, subjects completed the experimental protocol.

Experimental visits were scheduled at the same time of day ( $\pm 2 \mathrm{~h})$. Subjects were instructed to record their diet during the $24 \mathrm{~h}$ preceding the first experimental visit and to repeat this prior to the second visit. They were not specifically asked to refrain from the consumption of high- $\mathrm{NO}_{3}{ }^{-}$foods. Subjects were also instructed to arrive at the laboratory $\geq 3 \mathrm{~h}$ post-prandial, having avoided strenuous exercise and the consumption of alcohol in the $24 \mathrm{~h}$ preceding, and caffeine in the $8 \mathrm{~h}$ preceding, each experimental visit. For the duration of the study, subjects were asked to refrain from taking other dietary supplements, and also to avoid using antibacterial mouthwash as this inhibits the reduction of $\mathrm{NO}_{3}{ }^{-}$to $\mathrm{NO}_{2}{ }^{-}$in the oral cavity by eliminating commensal bacteria (Govoni et al. 2008).

\section{Supplementation}

Following the initial screening and familiarization visit, subjects were allocated to receive concentrated $\mathrm{NO}_{3}{ }^{-}$-rich beetroot juice (BR; beetroot juice; $\sim 6.4 \mathrm{mmol}$ of $\mathrm{NO}_{3}{ }^{-}$per $70 \mathrm{~mL}$; Beet it, James White Drinks Ltd., Ipswich, UK) or $\mathrm{NO}_{3}{ }^{-}$-depleted beetroot juice placebo (PL; 
placebo beetroot juice; 0.04 mmol $\mathrm{NO}_{3}{ }^{-}$per $70 \mathrm{~mL}$; Beet it, James White Drinks Ltd., Ipswich, UK) in a double-blind, randomized, crossover design. Subjects consumed 1 x $70 \mathrm{~mL}$ of their allocated supplement each day for 5 days and recorded the timing of each supplement. Consumption of each supplement was communicated to the research team via text or email. Compliance to the supplementation regimen was also assessed via questionnaires during each experimental visit. On the day of each experimental visit, subjects consumed $1 \times 70 \mathrm{~mL}$ of their allocated daily supplement 2.5 hours prior to arriving at the laboratory and commencing the exercise tests.

\section{Exercise protocol}

All exercise tests were performed indoors on a wooden surface on running lanes $2 \mathrm{~m}$ wide and $20 \mathrm{~m}$ long. During experimental visits, subjects first completed five running sprints from a stationary start as quickly as possible over a distance of $20 \mathrm{~m}$. Each sprint was separated by a period of $30 \mathrm{~s}$ walking recovery. Subjects began each sprint with the left foot positioned on a starting jump mat (Smartspeed, Fusion Sports, Australia). A timing gate system (Smartspeed, Fusion Sports, Australia) positioned at 0, 5, 10 and $20 \mathrm{~m}$ provided a randomly timed (between 1 and 4 s) flashing light and buzzer sound as stimuli to start each sprint. Reaction time to the stimuli, as well as 5, 10 and $20 \mathrm{~m}$ split times were recorded. Following a 5-min period of passive recovery, participants completed the Yo-Yo IR1 test until failure. The Yo-Yo IR1 test consisted of running repeated 2 x 20 m intervals, back and forth between the start, turn and finish markers at progressively increasing speeds indicated by audio bleeps from a portable audio device (see Krustrup et al. 2003). Each 2 x 20 m interval was separated by a $10 \mathrm{~s}$ active recovery period in which subjects would jog 2 x $5 \mathrm{~m}$ indicated by a marker placed behind the finishing line. When subjects failed twice to reach the finishing line at the time of the respective bleep, distance covered was recorded and used as the test result. Prior 
to, immediately following, and at $75 \%$ of the total distance covered in the familiarisation trial, subjects completed a computerised Stroop test (see “cognitive assessment”).

\section{Measurements}

\section{Blood analysis and blood pressure}

Upon arrival at the laboratory, a single resting blood sample $(\sim 4 \mathrm{~mL})$ was drawn from an antecubital vein into a lithium-heparin tube (Vacutainer, Becton-Dickinson, NJ, USA). The sample was centrifuged for $8 \mathrm{~min}$ at $4,000 \mathrm{rpm}$ and $4^{\circ} \mathrm{C}$ within $2 \mathrm{~min}$ of collection, and the plasma was then extracted and stored at $-80^{\circ} \mathrm{C}$ for later determination of $\left[\mathrm{NO}_{3}^{-}\right]$and $\left[\mathrm{NO}_{2}{ }^{-}\right]$ using a modified chemiluminescence technique as previously described (Wylie et al. 2013b). Then, following 10 min seated rest in a quiet room, three measurements of blood pressure were recorded using an automated sphygmomanometer (Dinamap Pro: GE Medical Systems, Tampa, FL).

\section{Cognitive assessment}

Subjects were asked to complete a Stroop test before, at $75 \%$ maximal distance and immediately following the Yo-Yo IR1 test. The Stroop test was delivered using E-Prime ${ }^{\circledR}$ 2.0 (Psychology Software Tools, Inc. 2013) and presented on a laptop screen positioned at the finish line marker of the Yo-Yo IR1 test. Subjects were instructed to respond as quickly and as accurately as possible to a series of text stings, as previously described (Thompson et al. 2015), using a custom-made keyboard with response reaction time and accuracy recorded. The duration of each Stroop test was 90 s. When the Stroop test was administered at $75 \%$ maximal distance in the Yo-Yo IR1 test, exercise was discontinued for exactly 2 min to allow sufficient time for the subject to position himself for the start of the Stroop test and to return to start position for the resumption of the Yo-Yo IR1 test. 


\section{Statistical analysis}

Differences between PL and BR in resting plasma $\left[\mathrm{NO}_{3}{ }^{-}\right]$and $\left[\mathrm{NO}_{2}{ }^{-}\right]$were analysed using a one-way ANOVA. Differences between PL and BR in distance covered during the Yo-Yo IR1 test, blood pressure and mean sprint reaction and performance times were analysed using paired-samples $t$-tests. Differences between PL and BR in reaction time and response accuracy to the Stroop tests before, during and after YoIR1 were analyzed using two-way, repeated-measures ANOVAs (supplement $\times$ time). Significant main and interaction effects were followed up with Fisher's LSD post hocs. Relationships between performance in PL and changes in performance following BR were analyzed using Pearson product moment correlation coefficients. All values are reported as mean \pm SD. Statistical significance was accepted at $P<0.05$.

\section{RESULTS}

The BR and PL treatments were well tolerated by the subjects and no adverse events were noted during the course of the study. The subjects reported that they complied fully with the supplementation protocol and with the instruction to record their diet during the $24 \mathrm{~h}$ preceding the first experimental visit and to replicate this prior to the second visit.

Blood pressure, plasma $\left[\mathrm{NO}_{2}^{-}\right]$and $\left[\mathrm{NO}_{3}^{-}\right]$

Compared to baseline, resting plasma $\left[\mathrm{NO}_{3}{ }^{-}\right]$was elevated by 8 -fold following BR (baseline: $41 \pm 20$ vs BR: $334 \pm 95 \mu \mathrm{M} ; P<0.01)$ but unaltered by PL $(44 \pm 16 \mu \mathrm{M} \mathrm{M} ; P>0.05)$ (Fig. 1A). Resting plasma $\left[\mathrm{NO}_{3}{ }^{-}\right]$was greater in $\mathrm{BR}$ compared to $\mathrm{PL}(P<0.05)$. Compared to baseline, resting plasma $\left[\mathrm{NO}_{2}^{-}\right]$was elevated following BR (baseline: $64 \pm 26$ vs BR: $222 \pm$ $130 \mathrm{nM} ; P<0.01)$ but unaltered following PL (68 $\pm 40 \mathrm{nM} ; P>0.05)$ (Fig. 1B). Resting plasma $\left[\mathrm{NO}_{2}{ }^{-}\right]$was greater compared to $\mathrm{PL}(P<0.01)$. Systolic BP was lower following $\mathrm{BR}$ 
supplementation (BR $117 \pm 7$ vs. PL $119 \pm 8$ mmHg; $P<0.05$ ). There was also a trend for a reduction in MAP following BR compared to PL (BR $79 \pm 15$ vs. PL $81 \pm 15 \mathrm{mmHg}$; $P=0.08$ ). There was no significant difference between BR and PL in diastolic BP (BR $64 \pm 6$ vs. PL $65 \pm 6$ mmHg; $P>0.05)$.

\section{Sprint performance}

Compared to PL, $20 \mathrm{~m}$ sprint time was improved by 1.2\% following BR supplementation (BR $3.98 \pm 0.18$ vs. PL $4.03 \pm 0.19$ s; $P<0.05$; Fig. 2). Moreover, there was a $2.3 \%$ and a $1.6 \%$ improvement in $5 \mathrm{~m}$ (BR $1.73 \pm 0.09$ vs. PL $1.77 \pm 0.09 \mathrm{~s} ; P<0.05)$ and $10 \mathrm{~m}(\mathrm{BR} 2.53$ \pm 0.12 vs. PL $2.57 \pm 0.12 \mathrm{~s} ; P<0.05$ ) split times, respectively (Fig. 2). Compared to PL, there was also a significant improvement in 5-10 m split time following BR (BR $0.80 \pm 0.04$ vs. PL $0.81 \pm 0.04 \mathrm{~s} ; P<0.05$ ), but not $10-20 \mathrm{~m}$ split time (BR $1.45 \pm 0.07 \mathrm{vs}$. PL $1.46 \pm 0.09 \mathrm{~s}$; $P>0.05)$. There was a weak but significant negative correlation between sprint performance in PL and the change in sprint performance observed following BR supplementation over $5 \mathrm{~m}$ ( $r$ $=-0.39 ; P<0.05), 10 \mathrm{~m}(r=-0.35 ; P<0.05)$ and $20 \mathrm{~m}(r=-0.37 ; P<0.05)$. There was no difference between BR and PL in reaction time (BR $0.33 \pm 0.19$ vs. PL $0.38 \pm 0.21 \mathrm{~s} ; P>0.05$; Fig. 2). There was no effect of testing order on sprint performance $(P>0.05)$.

\section{Yo-Yo IR1 performance}

Compared to PL, the distance covered in the Yo-Yo IR1 test was 3.9\% greater following BR supplementation (BR $1422 \pm 502$ vs. PL $1369 \pm 505$ m; $P<0.05$; Fig. 3). There was no effect of testing order on Yo-Yo IR1 test performance $(P>0.05)$.

\section{Cognitive performance}


The overall response time to the Stroop tasks was shorter in BR (612 $\pm 102 \mathrm{~ms})$ compared to PL (628 $\pm 103 \mathrm{~ms} ; P<0.05)$ corresponding to a $2.6 \%$ improvement in speed of reaction. Specifically, the greatest improvement in reaction time between BR and PL was observed during the cognitive tests performed at rest (BR: $615 \pm 98$ ms vs PL: $645 \pm 120$; $P<0.05$ ). There were no significant improvements in reaction time between BR and PL at the 75\% distance (BR: $612 \pm 104$ vs. PL: $621 \pm 92$ ms; P>0.05) or at exhaustion (BR: $608 \pm 106$ vs. PL: $619 \pm 97 \mathrm{~ms} ; P>0.05)$ during the Yo-Yo IR1 test. The overall accuracy of response was not different between BR (34.7 \pm 1.4 correct responses) and PL (34.6 \pm 1.5 correct responses) $(P>0.05)$ and there were no differences at any specific time point.

\section{DISCUSSION}

The main original finding of this study was that short-term dietary $\mathrm{NO}_{3}{ }^{-}$supplementation improved all-out sprint running performance over distances (5 m, $10 \mathrm{~m}$ and $20 \mathrm{~m}$ ) typically covered by team sports athletes during match-play. We have also confirmed that dietary $\mathrm{NO}_{3}{ }^{-}$ supplementation can improve performance in the team-sport-specific Yo-Yo IR1 test. Finally, our findings indicate that $\mathrm{NO}_{3}{ }^{-}$supplementation improves decision-making reaction time for the same response precision at rest, but not during or following team-sport-specific highintensity intermittent exercise. Therefore, these findings indicate that short-term dietary $\mathrm{NO}_{3}{ }^{-}$ supplementation can improve performance during short-duration maximal sprint running and high-intensity intermittent running, and support the notion that $\mathrm{NO}_{3}{ }^{-}$supplementation might enhance team sport performance.

Both plasma $\left[\mathrm{NO}_{3}{ }^{-}\right]$and $\left[\mathrm{NO}_{2}{ }^{-}\right]$were elevated following 5 days of $\mathrm{NO}_{3}{ }^{-}$supplementation in this study, consistent with previous studies (Larsen et al. 2006; Webb et al. 2008; Bailey et al. 2009; Vanhatalo et al. 2010). A greater circulating plasma $\left[\mathrm{NO}_{2}^{-}\right]$after short-term dietary 
$\mathrm{NO}_{3}{ }^{-}$supplementation would increase substrate for $\mathrm{NO}$ synthesis during exercise. The lower systolic BP reported in this study is also consistent with many (Webb et al. 2008; Kapil et al. 2010; Vanhatalo et al. 2010), but not all (Larsen et al. 2006), previous studies and supports the notion of $\mathrm{NO}$-mediated or $\mathrm{NO}_{2}^{-}$-mediated physiological signaling after dietary $\mathrm{NO}_{3}{ }^{-}$ supplementation. Therefore, the imposed dietary $\mathrm{NO}_{3}^{-}$intervention was successful at increasing systemic $\left[\mathrm{NO}_{2}^{-}\right]$and the potential for $\mathrm{O}_{2}$-independent $\mathrm{NO}$ generation.

\section{The effect of BR on maximal sprint running performance}

Although previous studies have reported improved maximal sprint cycling performance (Rimer et al. 2015; Thompson et al. 2015) and $180 \mathrm{~m}$ sprint running performance (Sandbakk et al. 2015) after $\mathrm{NO}_{3}{ }^{-}$supplementation, our study is the first to demonstrate that $\mathrm{NO}_{3}{ }^{-}$ supplementation can improve performance during 5, 10 and $20 \mathrm{~m}$ sprint running by $\sim 1-2 \%$. This finding is important since it suggests that $\mathrm{NO}_{3}{ }^{-}$supplementation can improve sprint performance within the exercise mode (i.e., running) and over the distances (5-20 m) that are typical of match-play in a wide range of team sports (Spencer et al. 2004; 2005).

Given the differences that have been reported in explosive force (Haider and Folland. 2014) and maximal power of inertial-load cycling (Coggan et al. 2015) following $\mathrm{NO}_{3}{ }^{-}$ supplementation, it might be anticipated that any ergogenic effect might be accentuated during the initial phase of all-out sprinting. Indeed, our findings indicate that the greatest improvement in sprint performance (2.3\%) occurred over the initial $5 \mathrm{~m}$. Moreover, BR continued to enhance speed between $5 \mathrm{~m}$ and $10 \mathrm{~m}$. Together with previous observations of improved sprint performance (Rimer et al. 2015; Thompson et al. 2015; Sandbakk et al. 2015), these findings strengthen the evidence base for using $\mathrm{NO}_{3}{ }^{-}$as a nutritional aid to enhance aspects of sprint running performance. 
The improved sprint performance after $\mathrm{NO}_{3}{ }^{-}$supplementation might be a function of the effects of $\mathrm{NO}_{3}{ }^{-}$supplementation on force production: 1) in type II muscle and 2) at high contraction velocities, since maximal sprinting requires both significant type II muscle recruitment and high contraction velocities (Greenhaff et al. 1994). Specifically, $\mathrm{NO}_{3}{ }^{-}$ supplementation has been shown to increase force production or performance: 1) during the initial stages of high-frequency contractions (Haider and Folland 2014); 2) at high, but not low, contraction velocities (Bailey et al. 2015; Coggan et al. 2015); and 3) in type II, but not type I, skeletal muscle in association with improved skeletal muscle calcium handling (Hernandez et al., 2012). Therefore, our results are consistent with observations of improved contractile function in studies using isolated muscle models and extend these findings to suggest that $\mathrm{NO}_{3}{ }^{-}$supplementation can enhance maximal sprint running performance over distances typically completed by team sports athletes during competition.

The effect of BR on performance during the YoYo IR1 test

Several studies have investigated the effects of $\mathrm{NO}_{3}{ }^{-}$supplementation on high-intensity intermittent exercise performance but the results have been ambiguous, likely due to marked differences in test protocol and the dose and duration of $\mathrm{NO}_{3}{ }^{-}$supplementation (Aucouturier et al. 2015; Bond et al. 2012; Christensen et al. 2013; Martin et al. 2014; Muggeridge et al. 2013; Thompson et al. 2015; Wylie et al. 2013; 2016). In the present study, we observed a 3.9\% improvement in the Yo-Yo IR1 test, which mimics the high-intensity running bouts of football match-play (Bangsbo et al. 2008), after short-term $\mathrm{NO}_{3}{ }^{-}$supplementation. This finding is consistent with our previous observation of improved Yo-Yo IR1 test performance (+4.2\%) after consuming a large $\mathrm{NO}_{3}{ }^{-}$dose $(29 \mathrm{mmol})$ over 36 hours prior to testing, and suggests that a similar performance gain can be achieved by ingesting a moderate $\mathrm{NO}_{3}{ }^{-}$dose (6.4 mmol $\mathrm{NO}_{3}{ }^{-}$per day) for 5 days. 
Given that the reduction of $\mathrm{NO}_{2}{ }^{-}$to $\mathrm{NO}$ is potentiated with decreasing $\mathrm{O}_{2}$ tension (Lundberg et al. 2008; van Faassen et al. 2009) and that $\mathrm{PO}_{2}$ is lower in type II compared to type I muscle (Behnke et al. 2003; McDonough et al. 2005), increasing plasma $\left[\mathrm{NO}_{2}{ }^{-}\right]$via $\mathrm{NO}_{3}{ }^{-}$ supplementation may enhance $\mathrm{NO}_{2}^{-}$-derived $\mathrm{NO}$ synthesis and thus performance during exercise at higher intensities. We have previously reported a fall in plasma $\left[\mathrm{NO}_{2}^{-}\right]$during high-intensity intermittent exercise following $\mathrm{NO}_{3}{ }^{-}$supplementation (Wylie et al. 2013a; Thompson et al. 2015). Moreover, the decline in plasma $\left[\mathrm{NO}_{2}^{-}\right]$was correlated to the improvement in exercise performance observed in these studies (Wylie et al. 2013a; Thompson et al. 2015). Given that circulating $\mathrm{NO}_{2}{ }^{-}$is an important correlate of exercise performance both in healthy, recreationally-active subjects (Dreissigacker et al. 2010; Rassaf et al., 2007) and in trained subjects (Lansley et al. 2011; Wilkerson et al. 2012), the greater Yo-Yo IR1 performance in BR may be attributable to enhanced generation of $\mathrm{NO}_{2}{ }^{-}$-derived NO during exercise.

$\mathrm{NO}_{3}{ }^{-}$ingestion has been shown to reduce the adenosine triphosphate (ATP) and phosphocreatine $(\mathrm{PCr})$ cost of muscle force production during high-intensity continuous (Bailey et al. 2010) and intermittent (Fulford et al. 2013) exercise. Furthermore, $\mathrm{NO}_{3}{ }^{-}$ supplementation has been reported to attenuate the slowing of $\mathrm{PCr}$ recovery observed in hypoxia, restoring $\mathrm{PCr}$ recovery kinetics following exercise to values observed in normoxia (Vanhatalo et al. 2011; 2014). It is known that, with increasing exercise intensity, a greater recruitment of type II fibres (Sale et al. 1987; Copp et al. 2010) and a slower rate of resynthesis of ATP and PCr in type II fibres between high intensity bouts occurs (Casey et al. 1996). Therefore, the effects of $\mathrm{NO}_{3}{ }^{-}$supplementation on muscle $\mathrm{PCr}$ utilisation during highintensity exercise (Bailey et al. 2010; Fulford et al. 2013) and on the rate of muscle PCr resynthesis following exercise (Vanhatalo et al. 2011; 2014) may be important determinants of the improved high-intensity intermittent exercise performance reported herein. 
In combination, the improved 5, 10 and 20 m maximal sprint running performance and the improved Yo-Yo IR1 performance suggest that short-term $\mathrm{NO}_{3}{ }^{-}$supplementation can improve several physical determinants of success in team sports and support the use of $\mathrm{NO}_{3}{ }^{-}$ supplementation as an ergogenic aid for team sports competitors. There were weak negative correlations between sprint performance in the PL condition and the magnitude of the improvement in sprint performance with BR supplementation $(\mathrm{r}=-0.35-0.39)$, indicating that the subjects with the poorest sprint performance benefited more from BR supplementation. This observation would be consistent with reports that $\mathrm{NO}_{3}{ }^{-}$supplementation is generally less effective in enhancing endurance performance in athletes with high levels of aerobic fitness (Wilkerson et al. 2012; Jones, 2014b; Porcelli et al. 2015) although some 20\% of elite athletes may still respond positively (Christensen et al. 2013; Boorsma et al. 2014). Further research is therefore required to determine whether the findings of the present study of recreational team sport players can be reproduced in highly-trained team sports athletes and/or whether a 'targeted' approach to individuals with relatively poor sprint performance might be recommended.

The effect of BR on cognitive performance during the YoYo IR1 test

There was no change in cognitive function, as inferred from response reaction time and accuracy during the Stroop test, during or following the Yo-Yo IR1 test. This finding conflicts with our previous observation of improved Stroop test performance (faster response reaction time for the same response accuracy) during a prolonged intermittent sprint-cycling protocol after $\mathrm{NO}_{3}{ }^{-}$supplementation (Thompson et al. 2015). These conflicting findings might be linked to the higher $\mathrm{NO}_{3}{ }^{-}$dose used in our previous study (12.8 $\mathrm{mmol} \mathrm{NO}_{3}{ }^{-}$per day for 7 days, Thompson et al. 2015) compared to the current study (6.4 $\mathrm{mmol} \mathrm{NO}_{3}{ }^{-}$per day for 5 days). Alternatively, or in addition to different $\mathrm{NO}_{3}{ }^{-}$dosing procedures, these inter-study 
differences in Stroop test performance might be related to the completion of numerous cognitive tests throughout the more lengthy exercise protocol used previously, thus increasing test sensitivity (Thompson et al. 2015), compared to the single $90 \mathrm{~s}$ Stroop test completed during a seated rest within the Yo-Yo IR1 test in the present study. Moreover, cognitive test performance typically becomes more variable in a fatigued state, rendering it more difficult to ascertain differences in performance between conditions.

\section{The effect of BR on cognitive performance at rest}

In contrast to results during exercise, $\mathrm{NO}_{3}{ }^{-}$supplementation improved decision-making reaction time to the Stroop tasks performed during the resting baseline period. This observation is consistent with Wightman et al. (2015) who reported improved cognitive function at rest in the serial 3s subtraction task following an acute dose of dietary $\mathrm{NO}_{3}{ }^{-}$. This was associated with improved cerebral blood flow in the prefrontal cortex at the onset of the task period. Similar to the serial 3s subtraction task, the Stroop task assesses the capacity for information processing (Besner and Roberts 2005) and performance in these tasks is related to the functioning of the prefrontal cortex. NO is pivotal to a number of cerebral processes including neurotransmission, vasodilation and neurovascular coupling (Aamand et al. 2013; Iadecola et al. 1999; Piknova et al. 2011; Rifkind et al. 2007). Dietary $\mathrm{NO}_{3}{ }^{-}$has been shown to improve regional brain perfusion (Presley et al. 2011), attenuate cerebral $\mathrm{O}_{2}$ extraction during mental processing (Thompson et al. 2014), and enhance coupling of cerebral blood flow to neuronal activity (Aamand et al. 2013). Therefore, the modulation of cerebral haemodynamics, especially in response to cognitive task performance (Wightman et al. 2015), may underpin the differences in response time between BR and PL in the present study. However, it is somewhat surprising that the greatest improvement in cognitive function was observed at rest and not during exercise when the difference between conditions in cerebral oxygenation is expected to be more pronounced and the potential for NO generation 
from $\mathrm{NO}_{2}{ }^{-}$reduction is expected to be increased (Lundberg et al. 2008; van Faassen et al. 2009). Further studies are required to investigate the effects of $\mathrm{NO}_{3}{ }^{-}$supplementation on cerebral oxygenation and cognitive function during high-intensity intermittent exercise.

\section{Experimental Considerations}

It is important to recognize that the efficacy of putative ergogenic aids in sport is related to a host of variables including subject characteristics (sex, age, training status), exercise modality and protocol (duration, intensity, continuous or intermittent), and dosing strategy (quantity, acute or chronic intake). In this respect, our study indicates that BR supplementation improves sprint and intermittent high-intensity exercise performance under the particular conditions of our investigation, namely in competitive but sub-elite team sport players consuming a moderate dose of $\mathrm{NO}_{3}{ }^{-}$for 5 days. Further clearly-defined and well-executed research studies are needed to test the various possible permutations (amongst subject type, exercise protocol, and dosing regimen) to better delineate the other circumstances in which $\mathrm{BR}$ or $\mathrm{NO}_{3}{ }^{-}$supplementation may, or may not be effective. A key strength of the present investigation was the recruitment of a large sample size and the employment of validated protocols to which the subjects were familiarized prior to commencement of the study. When differences between conditions are relatively small (i.e., 1-2\% for sprint performance), albeit but they are highly meaningful to sports performance outcomes (Hopkins et al. 1999), it is clearly important that studies are sufficiently powered to ensure that false conclusions are not drawn with regard to supplement efficacy. A limitation to our study was that we were unable to control subjects' diet but relied instead on the subjects recording their food consumption in the $24 \mathrm{~h}$ prior to the first experimental visit and replicating this prior to the second experimental visit. While the subjects reported that they had complied with this requirement, future studies might control pre-test diet more rigorously. It should also be noted that our study design (daily supplement intake for 4 days plus a final supplement intake $2.5 \mathrm{~h}$ before 
the exercise tests) does not allow us to differentiate between the effects elicited by chronic vs acute BR ingestion.

In conclusion, this study has made an important contribution to our understanding of the ergogenic potential of dietary $\mathrm{NO}_{3}{ }^{-}$supplementation for sprint and team sports athletes. Specifically, our results indicate that short-term supplementation (5 days) with a moderate $\mathrm{NO}_{3}{ }^{-}$dose (6.4 mmol NO${ }_{3}^{-}$per day) can improve performance in short-duration, all-out sprint runs (5-20 m) and high-intensity intermittent runs over distances that closely reflect those that are manifest during match-play in team sports such as hockey, football and rugby. Our results also indicate that $\mathrm{NO}_{3}{ }^{-}$supplementation can improve cognitive performance (faster response reaction time for the same response accuracy) in the Stroop test at rest, but not during or following a high-intensity intermittent running test. These findings support the use of $\mathrm{NO}_{3}{ }^{-}$ supplementation as a nutritional aid to enhance important physical determinants of team sport performance.

\section{Acknowledgements}

The authors thank Ella Jackson for assistance during exercise testing. Jonathan Fulford's salary was supported via an NIHR grant.

\section{Disclaimer}

This work was funded by PepsiCo Inc. and both James Carter and Lara Nyman are employees of PepsiCo Inc. The views expressed in this manuscript are those of the authors and do not necessarily reflect the position or policy of PepsiCo Inc. 


\section{REFERENCES}

Aamand R., Dalsgaard T, Ho YC, Moller A, Roepstorff A Lund TE (2013). A NO way to BOLD? Dietary nitrate alters the hemodynamic response to visual stimulation. Neuroimage 83:397-407.

Aucouturier J, Boissière J, Pawlak-Chaouch M, Cuvelier G, Gamelin FX (2015). Effect of dietary nitrate supplementation on tolerance to supramaximal intensity intermittent exercise. Nitric Oxide. 49:16-25

Bailey SJ , Fulford J, Vanhatalo A., Winyard P, Blackwell JR, Dimenna FJ, Wilkerson DP, Benjamin N and Jones AM (2010). Dietary nitrate supplementation enhances muscle contractile efficiency during knee-extensor exercise in humans. J Appl Physiol, 109:135-148.

Bailey SJ, Winyard P, Vanhatalo A, Blackwell JR, Dimenna FJ, Wilkerson DP, Tarr J, Benjamin N, Jones AM (2009) Dietary nitrate supplementation reduces the $\mathrm{O}_{2}$ cost of lowintensity exercise and enhances tolerance to high-intensity exercise in humans. $J$ Appl Physiol. 107:1144-1155.

Bailey SJ, Varnham RL, DiMenna FJ, Breese BC, Wylie LJ, Jones AM (2015) Inorganic nitrate supplementation improves muscle oxygenation, $\mathrm{O}_{2}$ uptake kinetics, and exercise tolerance at high but not low pedal rates. J Appl Physiol 118:1396-405.

Bangsbo J, Iaia FM, Krustrup P (2008) The Yo-Yo intermittent recovery test: a useful tool for evaluation of physical performance in intermittent sports. Sports Med. 38:37-51

Behnke BJ, McDonough P, Padilla DJ, Musch TI, Poole DC (2003). Oxygen exchange profile in rat muscles of contrasting fibre types. $J$ Physiol. 549:597-605 
Bond H, Morton L, Braakhuis AJ (2012) Dietary nitrate supplementation improves rowing performance in well-trained rowers. Int J Sport Nutr Exerc Metab 22(4):251-6.

Boorsma RK, Whitfield J, Spriet LL (2014) Beetroot juice supplementation does not improve performance of elite 1500-m runners. Med Sci Sports Exerc. 46(12):2326-34.

Casey A, Constantin-Teodosiu D, Howell S, Hultman E, Greenhaff PL (1996). Metabolic response of type I and II muscle fibers during repeated bouts of maximal exercise in humans. Am J Physiol. 271(1):38-43.

Cermak NM, Gibala MJ, Van Loon LJ (2012). Nitrate supplementation's improvement of 10km time-trial performance in trained cyclists. Int J Sport Nutr Exerc Metab. 22:64-71.

Christensen PM, Nyberg M, Bangsbo J (2013) Influence of nitrate supplementation on $\mathrm{VO}_{2}$ kinetics and endurance of elite cyclists. Scand J Med Sci Sports 23(1):21-31.

Coggan AR, Leibowitz JL, Kadkhodayan A, Thomas DP, Ramamurthy S, Spearie CA, Waller S, Farmer M, Peterson LR (2015). Effect of acute dietary nitrate intake on maximal knee extensor speed and power in healthy men and women. Nitric Oxide. 1;48:16-21

Copp SW, Hirai DM, Musch TI, Poole DC (2010). Critical speed in the rat: implications for hindlimb muscle blood flow distribution and fibre recruitment. J physiol. 588 (24):50775087

Dreissigacker U, Wendt, Wittke T, Tsikas D, Maassen N (2010) Positive correlation between plasma nitrite and performance during high-intensive exercise but not oxidative stress in healthy men. Nitric Oxide 23(2):128-135. 
Fulford J, Winyard PG, Vanhatalo A, Bailey SJ, Blackwell JR, Jones AM (2013) Influence of dietary nitrate supplementation on human skeletal muscle metabolism and force production during maximum voluntary contractions. Pflugers Arch. 465(4):517-28

Ferguson SK, Hirai DM, Copp SW, Holdsworth CT, Allen JD, Jones AM, Musch TI, Poole DC (2013). Impact of dietary nitrate supplementation via beetroot juice on exercising muscle vascular control in rats. J Physiol. 591(2):547-57

Govoni M, Jansson EÅ, Weitzberg E, Lundberg JO (2008) The increase in plasma nitrite after a dietary nitrate load is markedly attenuated by an antibacterial mouthwash. Nitric Oxide. 19(4):333-337.

Greenhaff PL, Nevill ME, Soderlund K, Bodin K, Boobis LH, Williams C, Hultman E. (1994) The metabolic responses of human type I and II muscle fibres during maximal treadmill sprinting. J Physiol. 478:149-155

Haider G, Folland JP (2014) Nitrate supplementation enhances the contractile properties of human skeletal muscle. Med Sci Sports Exerc. 46(12):2234-2243

Hernández A, Schiffer TA, Ivarsson N, Cheng AJ, Bruton JD, Lundberg JO, Weitzberg E, Westerblad H (2012) Dietary nitrate increases tetanic [Ca2+] i and contractile force in mouse fast-twitch muscle. J Physiol. 590(15):3575-83.

Hopkins WG, Hawley JA, Burke LM (1999). Design and analysis of research on sport performance enhancement. Med Sci Sports Exerc. 31(3):472-85.

Iadecola C (1993) Regulation of the cerebral microcirculation during neural activity: is nitric oxide the missing link? Trends Neurosci 16(6):206-14. 
Iadecola C, Zhang F, Niwa K, Eckman C, Turner SK, Fischer E, Younkin S, Borchelt DR, Hsiao KK, Carlson GA (1999) SOD1 rescues cerebral endothelial dysfunction in mice overexpressing amyloid precursor protein. Nat Neurosci 2(2):157-61.

Jones AM (2014a) Dietary nitrate supplementation and exercise performance. Sport Med. $44: 35-45$.

Jones AM (2014b) Influence of dietary nitrate on the physiological determinants of exercise performance: a critical review. Appl Physiol Nutr Metab. 39(9):1019-28.

Kapil V, Milsom AB, Okorie M, Maleki-Toyserkani S, Akram F, Rehman F, Arghandawi S, Pearl V, Benjamin N, Loukogeorgakis S, Macallister R, Hobbs AJ, Webb AJ, Ahluwalia A (2010) Inorganic nitrate supplementation lowers blood pressure in humans: role for nitritederived NO. Hypertension. 56:274-281

Krustrup P, Mohr M, Amstrup T, Rysgaard T, Johansen J, Steensberg A, Pedersen PK, Bangsbo J (2003) The yo-yo intermittent recovery test: physiological response, reliability, and validity. Med Sci Sports Exerc. 35:697-705

Krustrup P, Mohr M, Steensberg A, Bencke J, Kjaer M, Bangsbo J (2006) Muscle and blood metabolites during a soccer game: implications for sprint performance. Med Sci Sports Exerc. $38: 1165-1174$

Lansley KE, Winyard PG, Bailey SJ, Vanhatalo A, Wilkerson DP, Blackwell JR, Gilchrist M, Benjamin N, Jones AM (2011a) Acute dietary nitrate supplementation improves cycling time trial performance. Med Sci Sports Exerc. 43:1125-1131

Larsen FJ, Ekblom B, Sahlin K, Lundberg JO, Weitzberg E (2006). Effects of dietary nitrate on blood pressure in healthy volunteers. N Engl J Med. 355(26):2792-2793. 
Larsen FJ, Schiffer TA, Borniquel S, Sahlin K, Ekblom B, Lundberg JO, Weitzberg E (2011) Dietary inorganic nitrate improves mitochondrial efficiency in humans. Cell Metab. 13(2):149-59.

Lundberg J, Weitzberg E, Gladwin MT (2008) The nitrate-nitrite-nitric oxide pathway in physiology and theraputics. Nat Rev Drug Discov. 7(2):156-67.

Lundberg JO, Weitzberg E (2010) NO-synthase independent NO generation in mammals. Biochem Biophys Res Commun. 396(1):39-45.

Martin K, Smee D, Thompson K, Rattray B (2014) Dietary nitrate does not improve repeated sprint performance. Int J Sports Physiol Perform. 9(5):845-50

Masschelein E, Van Thienen R, Wang X, Van Schepdael A, Thomis M, Hespel P (2012) Dietary nitrate improves muscle but not cerebral oxygenation status during exercise in hypoxia. J Appl Physiol. 133(5):736-745

McDonough P, Behnke BJ, Padilla DJ, Musch TI, Poole DC (2005). Control of microvascular oxygen pressures in rat muscles comprised of different fibre types. $J$ Physiol. 563:903-913

Muggeridge DJ, Howe CC, Spendiff O, Pedlar C, James PE, Easton C (2013) The effects of a single dose of concentrated beetroot juice on performance in trained flatwater kayakers. Int $J$ Sport Nutr Exerc Metab 23(5):498-506.

Piknova B, Kocharyan A, Schechter AN, Silva AC (2011) The role of nitrite in neurovascular coupling. Brain Res. 1407:62-8. 
Porcelli S, Ramaglia M, Bellistri G, Pavei G, Pugliese L, Montorsi M, Rasica L, Marzorati M (2015) Aerobic fitness affects the exercise performance responses to nitrate supplementation. Med Sci Sports Exerc. 47(8):1643-51.

Presley TD, Morgan AR., Bechtold E, Clodfelter W, Dove RW, Jennings JM, Kraft RA, Bruce King S, Laurienti PJ, Jack Rejeski W (2011) Acute effect of a high nitrate diet on brain perfusion in older adults. Nitric Oxide. 24(1):34-42.

Rassaf T, Lauer T, Heiss C, Balzer J, Mangold S, Leyendecker T, Rottler J, Drexhage C, Meyer C, Kelm M (2007) Nitric oxide synthase-derived plasma nitrite predicts exercise capacity. Br J Sports Med. 41: 669-673

Rifkind JM, Nagababu E, Barbiro-Michaely E, Ramasamy S, Pluta RM, Mayevsky A (2007) Nitrite infusion increases cerebral blood flow and decreases mean arterial blood pressure in rats: a role for red cell NO. Nitric Oxide 16(4):448-56.

Rimer EG, Peterson LR, Coggan AR, Martin JC (2015). Acute Dietary Nitrate Supplementation Increases Maximal Cycling Power in Athletes. Int J Sports Physiol Perform. [Epub ahead of print]

Sandbakk SB, Sandbakk Ø, Peacock O, James P, Welde B, Stokes K, Böhlke N, Tjønna AE (2015). Effects of acute supplementation of L-arginine and nitrate on endurance and sprint performance in elite athletes. Nitric Oxide. 48:10-15.

Sale DG (1987). Influence of exercise and training on motor unit activation. Exerc Sport Sci Rev. 5:95-151. 
Spencer M, Lawrence S, Rechichi C, Bishop D, Dawson B, Goodman C (2004) Time-motion analysis of elite field hockey, with special reference to repeated-sprint activity. J Sports Sci 22(9):843-50.

Spencer M, Bishop D, Dawson B, Goodman C (2005). Physiological and metabolic responses of repeated-sprint activities:specific to field-based team sports. Sports Med. 35(12):1025-44.

Stamler JS, Meissner G (2001). Physiology of nitric oxide in skeletal muscle. Physiol Rev. 81:209-37.

Thompson C, Wylie LJ, Fulford J, Kelly J, Black MI, McDonagh ST, Jeukendrup AE, Vanhatalo A, Jones AM (2015) Dietary nitrate improves sprint performance and cognitive function during prolonged intermittent exercise. Eur J Appl Physiol. 115(9):1825-34

Umbrello M, Dyson A, Feelisch M and Singer M (2013). The key role of nitric oxide in hypoxia: hypoxic vasodilation and energy supply-demand matching. Antioxid. Redox Signal. 2013; 19:1690-710.

Van Faassen EE, Bahrami S, Feelisch M, Hogg N, Kelm M, Kim-Shapiro DB, Kozlov AV, Li H, Lundberg JO, Mason R (2009) Nitrite as regulator of hypoxic signaling in mammalian physiology. Med Res Rev. 29:683-741.

Vanhatalo A, Bailey SJ, Blackwell JR, Dimenna FJ, Pavey TG, Wilkerson DP, Benjamin N, Winyard P, Jones AM (2010) Acute and chronic effects of dietary nitrate supplementation on blood pressure and the physiological repsonses to moderate-intensity and incremental exercise. Am J Physiol Regul Integr Comp Physiol. 299(4):1121-31. 
Vanhatalo A, Fulford J, Bailey SJ, Blackwell JR, Winyard PG, Jones AM (2011) Dietary nitrate reduces muscle metabolic perturbation and improves exercise tolerance in hypoxia. $\mathrm{J}$ Physiol 589:5517-5528

Vanhatalo A, Fulford J, Bailey SJ, Blackwell JR, Winyard PG, and Jones AM (2014) Dietary nitrate reduces muscle metabolic perturbation and improves exercise tolerance in hypoxia. $J$ Physiol. 589(22):5517-5528.

Webb AJ, Patel N, Loukogeorgakis S, Okorie M, Aboud Z, Misra S, Rashid R, Miall P, Deanfield J, Benjamin N, MacAllister R, Hobbs AJ, Ahluwalia A (2008). Acute blood pressure lowering, vasoprotective, and antiplatelet properties of dietary nitrate via bioconversion to nitrite. Hypertension. 51(3):784-790

Wightman EL, Haskell-Ramsay CF, Thompson KG, Blackwell JR, Winyard PG, Forster J, Jones AM, Kennedy DO (2015). Dietary nitrate modulates cerebral blood flow parameters and cognitive performance in humans: A double-blind, placebo-controlled, crossover investigation. Physiol Behav. 149:149-58

Wilkerson DP, Hayward GM, Bailey SJ, Vanhatalo A, Blackwell JR, Jones AM (2012) Influence of acute dietary nitrate supplementation on 50 mile time trial performance in welltrained cyclists. Eur J Appl Physiol. 112:4127-4134

Wylie LJ, Mohr M, Krustrup P, Jackman SR, Ermiotadis G, Kelly J, Black M I, Bailey SJ, Vanhatalo A, Jones AM (2013a) Dietary nitrate supplementation improves team sportspecific intense intermittent exercise performance. Eur J Appl Physiol. 113(7):1673-84.

Wylie LJ, Kelly J, Bailey SJ, Blackwell JR, Skiba PF, Winyard P, Jeukendrup AE, Vanhatalo A, Jones AM (2013b) Beetroot juice and exercise: pharmacodynamic and dose-response relationships, J Appl Physiol. 115(3):325-36. 
Wylie LJ, Bailey SJ, Kelly J, Blackwell JR, Vanhatalo A and Jones AM (2016). Influence of beetroot juice supplementation on intermittent exercise performance. Eur J Appl Physiol. 116: 415-425. 


\section{FIGURE LEGENDS}

Figure 1: BR elevated plasma $\left[\mathrm{NO}_{2}{ }^{-}\right]$by $248 \%$ compared to baseline and $226 \%$ compared to PL (panel A). BR elevated plasma $\left[\mathrm{NO}_{3}{ }^{-}\right]$by $710 \%$ compared to baseline and $666 \%$ compared to PL (panel B). * $P<0.001$ compared to PL; \# $P<0.001$ compared to baseline.

Figure 2: Sprint performance was improved in BR compared to PL. ${ }^{*} P<0.05$.

Figure 3. The distance covered in the Yo-Yo IR1 test was 3.7\% greater in BR compared to PL. The dashed lines indicate individual responses and the solid line indicates the group mean $( \pm \mathrm{SE}) .{ }^{*} P<0.05$. 